\title{
The marital satisfaction and its relative factors among older adults
}

\begin{abstract}
Marital satisfaction as an important aspect of marital quality has a significant role in family functioning. This study was conducted to evaluate the levels of marital satisfaction and its related factors among older. A cross-sectional study was carried out on a sample of 400 hospitalized older adults. The cluster sampling method was applied for choosing participants. The Farsi Enrich questionnaire was used for gathering data. Data were analyzed using the Chi-square test, t-test, ANOVA and binary logistic regression at the multivariate model.
\end{abstract}

Among the respondents, $40.6 \%$ were females, $69.8 \%$ were Illiterate and $14.7 \%$ had a Physical disorder. The mean age of the participants was $65.2 \pm 5.7$ years. The mean overall marital satisfaction scores in the men and women of older adults were $110.9 \pm 9.78$ and $109.70 \pm 10.56$, respectively. Marital satisfaction no had significant relationship with gender. In univariate analysis, significant difference was observed among marital satisfaction with level of education and remarriage $(P<0.05)$. A significant correlation was found between length of marriage and marital satisfaction scores $(r=0.30, P=0.001)$. In multivariate analysis, the variables of gender, remarriage and having physical disorders stayed in the model that had a statistical relationship with the marital satisfaction $(\mathrm{p}<0 / 05)$. It could be inferred that older adult have undoubtedly better feeling about their marital life that cause to effective discussion for understanding each other.

Keywords: marital, satisfaction, older adults, significant correlation, statistical relationship
Volume I Issue 4 - 2016

\author{
Takbiri Boroujeni Anahita,' Izadi Avanji \\ Fateme Sadat,' Ismail Azizi Fini, ${ }^{2}$ Gilasi \\ Hamidreza, ${ }^{3}$ Mirbagher Ajorpaz Neda ${ }^{4}$ \\ 'Faculty of Nursing and Midwifery, Kashan University of Medical \\ Sciences, Iran \\ ${ }^{2} \mathrm{School}$ of Nursing and Midwifery, Tehran University of Medical \\ Sciences, Iran \\ ${ }^{3}$ Department of biostatics and epidemiology, Kashan University \\ of Medical Science, Iran \\ ${ }^{4}$ Department of Surgical Technology, Kashan University of \\ Medical Sciences, Iran
}

Correspondence: Izadi Avanji Fateme Sadat, Faculty of Nursing, Kashan University of Medical Sciences, Iran, Tel +9 836 I 5554002 I,Email Fs.lzadi@gmail.com

Received: November 12, 2016 | Published: December 13, 2016

\section{Introduction}

In spite of widely studies about marital satisfaction, many researchers have claimed that some aspects still need to be explained. Marital satisfaction as an important aspect of marital quality ${ }^{1}$ has significant role in family functioning that means people's perception of their marital relationship ${ }^{2}$ or the satisfaction that is experienced by couples. ${ }^{3}$ Undeniably, marital satisfaction occurs over time due to the need for identifying personality traits, communication and behavioral patterns and adapting couple's preferences. ${ }^{4}$ What is more, marital satisfaction has evidently been effective on almost all aspects of life which cause to improving family functioning, facilitate parent's role as well as increased health and longevity and finally increased life satisfaction. ${ }^{5}$ Hence, what it can be said is the undeniable role of marital satisfaction in family health. ${ }^{6}$ Moreover, Pleasant and relaxing couple's relationship is not only suitable in order to their growth and flourishing, but also it is essential for children's development and growth. ${ }^{7}$ So, it could be definitely considered as a factor for achieving life's goals and is effectively influenced mental disorders in the community. ${ }^{8}$ Although, results of a study shows that almost all couples have high marital satisfaction in early years of marriage life but, it painfully decreases over time when their age increases. ${ }^{9}$ On the other hand, lack of marital satisfaction has important consequences such as impairment in social interaction, feelings of isolation and loneliness, lower life satisfaction and family disputes that note the importance of this factor again. ${ }^{10}$

Results of some studies have shown that factors such as social, economic (income) and employment situation as well as personality, cognitive, religious factors besides, dating before marriage, spousal age, number of children, couples' age gap, addiction, education, gender, disease and sexual satisfaction involved in marital satisfaction. ${ }^{2,5,11-13}$ It is worth to mention that Chiung et al. ${ }^{14}$ have claimed that factors affecting marital relationship is obviously vary in different culture. ${ }^{14}$ The most marital dissatisfaction is related to women ${ }^{15}$ and in another study has been reported that marital satisfaction in women increases with age. ${ }^{11}$ Nevertheless, Amato asserted that marital happiness have been equal among men and women. ${ }^{16}$ besides, the results of some studies show satisfaction about sexual activity is one of the most important factors affecting marital satisfaction, so lower satisfaction will occurs when sexual activity reduce due to aging. ${ }^{4,10,11,14,15}$

Additionally, having low levels of education in large percentage of adults has been shown through a study could cause to lower level of satisfaction, ${ }^{4}$ since high education levels leads to better communication and conflict resolution skills in marriage. ${ }^{2}$ In spite of this results, a few studies have been conducted about elderly people in Iran have shown inconsistent results. Considering the growing elderly population in our society, this study aimed to examine the marital satisfaction and the associated demographic factors in Kashan city.

\section{Methodology}

This cross-sectional study was conducted on 400 older adults covered through health centers of Kashan. Then, the samples were selected by cluster sampling method after receiving ethical approval from the ethics committee. Kashan has 30 health centres that 8 centres were randomly selected among them and sample were randomly selected from the list of persons registered in each centre. Next, going to their homes, questionnaires were completed by the interviewer. 
Inclusion criteria include aged 65 and older, having living spouse, no mental illness, and independence in daily activities, Iranian nationality for both spouse, ability to answer questions and finally, their tendency to participate in the study. In addition, a two parts questionnaires includes demographic (age, gender, education, number of children, employment, length of marriage, smoking history) and Enrich questionnaire (Marital satisfaction questionnaire) were applied for collecting data.

The guide questionnaire with Likert scale questions included: strongly agree, agree, neither agree nor disagree, disagree, totally disagree is answered and they are awarded 1 to 5 score and should not be forgotten that 19 numbers of questions are scored in reverse. Also, 35 and 157 are the minimum and maximum score respectively. 0-15 scores indicate high dissatisfaction, 35-16 percent somewhat dissatisfied, 60-36 percent somehow lucky, 80-61 percent higher satisfaction.

Enrich questionnaire has been designed by Elson in 1989 for the first time in order to measuring marital communication which includes some sub-scales such as ideal distort (5 questions), sexual satisfaction (10 questions), communication (10 questions) and Conflict Resolution (10 questions). Validity and reliability of this questionnaire has been measured In Iran several times. Sub-scales reliability was measured by Cronbach's alphas coefficient which appropriate rate was gained (from 0.80 to 0.92 ). ${ }^{17}$ Identically, in current study questionnaire reliability was measured by Cronbach's alphas coefficient and a group of 10 elderly people was considered as population who were assessed after 10 day again for examining questionnaire reliability. The Correlation coefficient is equal to 0.91 . Commonly, SPSS 16 software was applied for analysis the data gathered during the research. At the first stage, Data were tested through T- test and ANOVA and then the variables by $\mathrm{P} \leq 2$ were selected for logistic regression model.

\section{Findings}

Among the respondents, $40.6 \%$ were females, $69.8 \%$ were Illiterate and $14.7 \%$ had a Physical disorder. The mean age of the participants was $65.2 \pm 5.7$ years. Demographic and clinical characteristic of older adults is stated in Table 1. Four hundred older adults with an average age of $65.2 \pm 5.7$ participated in this study. The average of total score of marital satisfaction of the older adults was $107.89 \pm 12.3$ and 222 subjects $(55.5 \%)$ had a high marital satisfaction. The mean score marital satisfaction was 110.9 (9.8) in men with and 109.7 (10.6) in women. No significant difference was observed between male and female older adults. The comparison of dimensions of marital satisfaction among older adult showed that mean dimension of sexual satisfaction score was significantly different with gender. However, the mean communication, conflict resolution and ideal distort scores were not significantly different among male and female of older adults Table 2.

Table I Demo graphic characteristics of older adults in the study

\begin{tabular}{llll}
\hline Qualitative variables & Number & (\%) \\
\hline \multirow{2}{*}{ Gender } & Women & 159 & $(40.6)$ \\
& Men & 241 & $(59.4)$ \\
Smoking & Yes & 88 & $(22.4)$ \\
& No & 312 & $(77.6)$ \\
& Self- employed & 151 & $(37.8)$ \\
Job & governmental & 112 & $(28)$ \\
& Housekeeper & 113 & $(28.2)$ \\
Education & Worker & 24 & $(6)$ \\
& Illiterate & 274 & $(69.8)$ \\
Physical disorder & Literate & 126 & $(30.2)$ \\
Quantitative variable & & 59 & $(14.7)$ \\
Age & No & 341 & $(85.3)$ \\
Length of marriage & & mean $\pm S D$ & Rang \\
Number of children & & $65.2 \pm 5.7$ & $60-87$ \\
& & $41.7 \pm 5.9$ & $24-70$ \\
\hline
\end{tabular}

Table 2 The Comparison of average marital satisfaction among elderly men and women

\begin{tabular}{lllll}
\hline Dimensions of marital satisfaction & Gender & Mean\&Sd & Scores (percentage) & P \\
\hline \multirow{2}{*}{ Sexual satisfaction } & women & $31.35 \pm 4.76$ & $62 / 7$ & $0 / 003$ \\
& men & $33.56 \pm 5.03$ & $67 / I$ & \\
Communication & women & $31.42 \pm 4.21$ & $62 / 8$ & $0 / 21$ \\
& men & $30.73 \pm 3.45$ & $61 / 4$ & $0 / 07$ \\
Conflict resolution & women & $30.61 \pm 3.46$ & $62 / 1$ & \\
& men & $29.67 \pm 3.57$ & $59 / 3$ & $0 / 07$ \\
Ideal distort & women & $16.30 \pm 2.58$ & $65 / 2$ & \\
& men & $17.01 \pm 2.54$ & 68 & $0 / 38$ \\
Total score & women & $109.70 \pm 10.56$ & $62 / 7$ & \\
Total score & men & $110.91 \pm 9.78$ & $63 / 4$ & 62 \\
\hline
\end{tabular}


In unvariate analysis, significant difference was observed among marital satisfaction and Remarriage $(\mathrm{P}<0.01)$ and literacy level $(\mathrm{P}<0.05)$. However, gender, job, Physical disorder and Smoking did not have significant relationship with marital satisfaction Table 3. The mean length of marriage score was $41.7 \pm 5.9$. The A significant correlation was found between length of marriage and total score of marital satisfaction ( $\mathrm{r}=0.30, \mathrm{P}=0.001)$. No significant correlation was observed between age and number of children and total score of marital satisfaction.

Table 3 The relationship between marital satisfaction scores according to demographic variables

\begin{tabular}{|c|c|c|c|}
\hline Variables & Levels of variable & Mean $\pm S d$ & $\mathbf{P}$ \\
\hline Gender & $\begin{array}{l}\text { women } \\
\text { men }\end{array}$ & $\begin{array}{l}10.3 \pm 106.2 \\
9.5 \pm 107.7\end{array}$ & 0.06 \\
\hline Remarriage & $\begin{array}{l}\text { yes } \\
\text { no }\end{array}$ & $\begin{array}{l}10.25 \pm 100.8 \\
9.45 \pm 108\end{array}$ & 0.001 \\
\hline Education & $\begin{array}{l}\text { Illiterate } \\
\text { literate }\end{array}$ & $\begin{array}{l}105.4 \pm 10.6 \\
112.9 \pm 8.7\end{array}$ & 0.03 \\
\hline Job & $\begin{array}{l}\text { Self- employed } \\
\text { governmental } \\
\text { Housekeeper } \\
\text { Worker }\end{array}$ & $\begin{array}{l}106.4 \pm 9 \\
106.96 \pm 10.9 \\
107.1 \pm 9.4 \\
110.2 \pm 9.8\end{array}$ & 0.12 \\
\hline Physical disorder & $\begin{array}{l}\text { yes } \\
\text { no }\end{array}$ & $\begin{array}{l}105.96 \pm 10.9 \\
107.1 \pm 9.4\end{array}$ & 0.09 \\
\hline Smoking & $\begin{array}{l}\text { yes } \\
\text { no }\end{array}$ & $\begin{array}{l}9.8 \pm 105.4 \\
107.56 \pm 9.8\end{array}$ & 0.36 \\
\hline
\end{tabular}

Table 4 Multiple logistic regression model for determining the predictors of marital satisfaction in older adults

The Regression logistic with backward stepwise method was used for the multivariate analysis. The variables of gender $(\mathrm{OR}=2.9)$, job $(\mathrm{OR}=0.119)$, Remarriage $(\mathrm{OR}=0.311)$ and having Physical disorder $(\mathrm{OR}=0.237)$ stayed in the model that had a statistical relationship with the marital satisfaction. On the other hand, the marital satisfaction of men older adults was better than women. The individuals who had no remarriage had more marital satisfaction. Also having Physical disorder was result in decrease of marital satisfaction Table 4 .

\begin{tabular}{|c|c|c|c|c|c|c|c|}
\hline \multirow[t]{2}{*}{ Variable } & \multirow[t]{2}{*}{$\beta$} & \multirow[t]{2}{*}{ S.E. } & \multirow[t]{2}{*}{ Wald } & \multirow[t]{2}{*}{ Pv } & \multirow[t]{2}{*}{$\operatorname{Exp}(B)$} & \multicolumn{2}{|c|}{ 95.0\% C.I. for $\operatorname{Exp}(B)$} \\
\hline & & & & & & Lower & Upper \\
\hline Gender & 1.068 & 0.431 & 6.137 & 0.013 & 2.909 & 1.25 & 6.771 \\
\hline Self-Employed & & & 15.755 & 0.001 & & & \\
\hline Governmental & 0.255 & 0.308 & 0.685 & 0.408 & 1.29 & 0.706 & 2.357 \\
\hline Housekeeper & 0.685 & 0.486 & 1.991 & 0.158 & 1.985 & 0.766 & 5.143 \\
\hline Worker & -2.132 & 0.632 & 11.387 & 0.001 & 0.119 & 0.034 & 0.409 \\
\hline Remarriage & -1.116 & 0.637 & 10.127 & 0.001 & 0.311 & 0.152 & 0.639 \\
\hline Having physical disorder & $-1.44 \mid$ & 0.364 & $|5.7| \mid$ & 0 & 0.237 & 0.116 & 0.483 \\
\hline Constant & -1.56 & 0.574 & 7.372 & 0.007 & 0.21 & & \\
\hline
\end{tabular}

\section{Discussion}

The result shows that elderly people have undoubtedly better feeling about their marital life that cause to effective discussion for understanding each other. ${ }^{17}$ It seems that couples who have more leisure time and hobbies in common, have more emotional and verbal communications, which cause to improving physical and mental health and increasing their self- satisfaction and marital satisfaction. ${ }^{7}$
Couples, who are satisfied with their marriage, consider marital relations as a supportive relationship. ${ }^{12}$ In our traditional and religious society, due to the social and religious participation in family routines activity, there is greater understanding between family members. It could be considered because of religious beliefs which cause to controlling anger and considering the God when anger Occurs. Thus, it seems that conflict between couples is prevented as a result of religious beliefs. The results show that although marital satisfaction 
in the elderly couples was similar in univarate analysis, but after removing the confounding effect these differences was significant. However, the multivariate analysis showed that marital satisfaction was higher in men than women. The reason can be attributed to the higher expectations of women rather men. In addition, feelings about relationships or marital satisfaction are not easily expressed in our society by women.

Results of Guo \& Huang ${ }^{12}$ also showed that the mean of marital satisfaction score was higher in men than women and. In contrast to these results, Amato is expressed that satisfaction and happiness were similarly equal in men and women. ${ }^{16}$ In another point of view, the results of Bakhshi et al. ${ }^{11} \&$ King et al. ${ }^{8}$ have shown that marital satisfaction in women is positively associated with aging. To be more precise, one of the most influential factors affecting marital satisfaction is sexual satisfaction. Additionally, aging causes disturbances in sexual function and activity. ${ }^{15,18-20}$ So, couples expectations and demands changes and mutual attraction reduces. ${ }^{18}$ Alphonse and Jose also considered age as a factor involving to sexual adaptation. ${ }^{21}$ For explaining the contradictory findings, it can be argued that it is probably due to the differences between age groups of the samples in different studies. In addition, according to Bramon study geographical differences affecting common life satisfaction..$^{22}$ Thus, in spite of increasing marital satisfaction with age, Satisfaction among men and women are not equal. Therefore, in order to extend the results, geographical and cultural differences must also be considered. Occupation and income was another factor influences on marital satisfaction interacting with other variables in elderly groups.

Most of marital satisfaction has been among housewives, then individuals with governmental occupation, next self-employed people and ultimately workers. This is probably due to the lack of economic stability for self-employed people that decrease marital satisfaction.

The results of Sadegh Moghadam et al. ${ }^{12}$ showed that job satisfaction is directly associated with marital satisfaction. Overall, Job insecurity and low income followed by concern about economic problems and lower marital satisfaction. Thus, it seems that sufficient income cases to high levels of marital satisfaction. ${ }^{13}$ Vaijayanthimala et al. ${ }^{23}$ have suggested that marital satisfaction is influenced by income and employment. Identically, Zainah et al. ${ }^{1} \&$ Trudel, ${ }^{24}$ and Chou have also shown that high income increases marital satisfaction which is consistently associated with the result of current study. Similarly, the result of another study indicated that mental health of husbands, who their wives are not housewives, is more than others. So, it seems that Women's employment, if that would not conflict with their roles as wives, have a positive impact on their husbands, children and also their social interactions. ${ }^{13}$ In addition, due to the social interactions of being employed and also their friends and social relationships, marital satisfaction increases.

The results of the present study have shown that remarriage decreases marital satisfaction. In other words, People who remarried were less satisfied with their marriages than those who did not remarry. Ahmadi et al. ${ }^{3}$ also emphasized on this issue in their study. ${ }^{4}$ But the results of Bograd et al. ${ }^{25}$ study are inconsistent with this conclusion.

In explaining these findings, it can be said that the people with marital problems in their first marriage will experience similar problems in subsequent ones which cause to lower marital satisfaction rather first marriage. To put it simply, instability of first marital caused instability in the subsequent marriage. , $16,26^{2}$
The results of this study showed that there was no relationship between overall satisfactions of marriage and education. The reason probably is the low educational level of elderly participants (both sexes) in this study. It can be added that studies have shown that increasing the education level of the couples cause to understanding each other more,

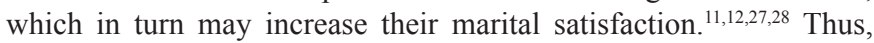
High education level could undoubtedly improve communication and conflict resolution skills between couples. It also can improve the economic situation of families. As a consequence, pressure of economic problems is reduced and consequently marital satisfaction wills improve. $^{2}$

Number of children was the other demographic variables were examined in this study. According to results of this study, there was no relationship between overall marital satisfaction and the number of children. Nevertheless, Edwards and White ${ }^{24}$ were stated that no children are positively correlated with marital satisfaction. ${ }^{1}$ Also, number of children has been considered a factor in marital satisfaction by Guo \& Huang. ${ }^{11}$

Bakhshi et al. ${ }^{10}$ also have mentioned to children as a factor involved in marital satisfaction. Blumel concluded that child care (two or more) increases quality of life. ${ }^{29}$ In another study it was stated that the number of children is associated with sexual compatibility (34) and having children is cause to stability of marriage. ${ }^{30}$ Since having children is one of the young couple's life goals, ${ }^{31}$ therefore, the number of children in old age has no significant impact on marital satisfaction.

On the other hand, other studies about different culture and also different age have reported that factors affecting marital relationship is obviously vary in different culture. All in all, it is suggested that more investigations needs to be applied in order to reliable Results. Oddly enough, there was no relationship between marital satisfaction lengths of marriage presumably because of high average of marriage length about all elderly people in this study that contributes to marital satisfaction. It is claimed that as a result of achieving compatibility over time, couples experience less conflict and stress. ${ }^{1}$

So, as Jose and Alfons have stated lengths of marriage is related to marital satisfaction; however, in this study due to the high average of marriage length about all elderly people there was no relationship between marital satisfaction lengths of marriage. While there was no relationship between marital satisfaction and smoking in this study, Himish et al. ${ }^{32}$ have reported that smoking or alcohol consumption decreases marital satisfaction. ${ }^{33}$ Additionally, negative relationship between marital satisfaction and smoking has been reported. ${ }^{34}$ In relation with this issue, Addis et al have assessed that sexual satisfaction in women who were not smoke is more than other. ${ }^{35}$ Because of the small number of participants in this study reported a history of smoking and none of them were currently smoking and drugs, there was no relationship between smoking and overall marital satisfaction. ${ }^{36}$

\section{Conclusion}

Considering current study has been compared the marital satisfaction in elderly men and women, showed that older people were in the high satisfaction range. Due to this study was conducted in a traditional and religious society which contributes to marital satisfaction, this result was not unexpected. In addition, lower marital satisfaction in women rather than men is related to higher women's 
expectations than men or more women's restrictions in traditional societies that cause to isolation and lack of women's comfort, especially about sexual matters with their spouses. Therefore, it is recommended to educate and raise awareness of women's culture in order to obtain self-express and also self esteem.

\section{Acknowledgements}

None.

\section{Conflict of interest}

The author declares no conflict of interest.

\section{References}

1. Zainah AZ, Nasir R, Ruzy Suliza H, et al. Effects of Demographic Variables on Marital Satisfaction. Asian Social Science. 2012;8(9):4649.

2. David Eugene Bel. The relationship between distal religious and proximal spiritual variables and self-reported marital happiness. Florida State University, USA: Springer; 2009.

3. Rubell S. Exploring contributions of relational self to man's identity self. Journal of Counseling and Development. 2004;82(4):184-196.

4. Ahmadi K, FathiAshtiani A, Navabinejad S. Underlying factorsinterpersonal communication-Mutual influence of marital adjustment. Journal of Family Research. 2005;221-237.

5. Hosseininasab D, Hashemi Nosrat Abad T, Fotouhibanab S. The relationship between religious orientation and marital adjustment Quarterly-University psychology research. 2009;4(14):82-95.

6. Byrne M, Carr A, Clark M. The efficacy of behavioral couples therapy and emotionally focused therapy for couple distress. Journal of Contemporary Family Therapy. 2004;26(4):361-384.

7. Monjazy F, ShafiAbadi A, Sudani M. Association of Islamic and religious attitudes on improving marital satisfaction. Journal of Behavioral Science Research. 2012;10(10).

8. King A, Bernardy N. Stressfull events, personality and mood disturbance: gender difference in alcoholics and problem drinkers. Addict Beha. 2003;28(1):171-187.

9. Halford WK, Sanders MR, Behrens BC. Can Skills training prevent relationship problems in at-risk couples? Four-Year effects of a behaviora relationship education program. Journal of Family Psychology. 2001;15(4):750-768.

10. Motavalli R, Ozgoli G, Bakhtiari M, et al. Marital satisfaction and marital intimacy in employed and unemployed pregnant women of ardebil city. Journal of University of medicin Sciences of Ardabil. 2008;9(4):315-324.

11. Bakhshi H, Asadpour M, Khodadadizadeh A. Correlation between marital satisfaction and depression among couples in Rafsanjan. Journal of Qazvin Univ of Medical Science. 2007;11(2):37-43.

12. Guo B, Huang J. Marital and sexual satisfaction in Chinese Families: Exploring the moderating Effects. Journal of Sex and Mental therapy. 2005;31(1):21-29.

13. Sadegh Moghadam L, Askari F, Marouzi P, et al. Comparison of marriage satisfaction in housewives and employed women and their husbands in Gonabad. Ofogh-e-danesh. Journal of Gonabad University of Medical Sciences and Health Services. 2006;12(2):45-50.

14. Chiung A, Shen T. Factors in the marital relationship in a changing society. International Social Work. 2005;48(3):325-340.
15. Stacy Tessler L, L Philip S, Edward OL, et al. A study of sexuality and health among older adults in the united states. New England Journal of Medicine. 2007;357:762-74.

16. Amato PR, Booth A, Johnson DR, et al. Alone together: How marriage in American is changing. Cambridge, England: Harvard University Press; 2007.

17. Asoodeh MH, KhaliliSh, Lavasani M, et al. Enrich couple questionnaire; 2010.

18. Rahmani A, Merghati Khoei E, Sadeghi N, et al. Relationship between sexual pleasure and marital satisfaction. Iran Journal of Nursing. 2011;24(70):82-90.

19. Huang AJ, Subak LL, Thom DH, et al. Sexual function and aging in racially and ethnically diverse women. Journal of the American Geriatrics Society. 2009;57(8):1362-1368.

20. Hurd Clarke L. Older women and sexuality: experiences in martital relationship across the life course. Can J Aging. 2006;25(2):129-140.

21. Jose O, Alfons V. Do demographics affect marital satisfaction. Journal of sex and Marital Therapy. 2007;33(1):73-85.

22. Sheikholeslami R, Nejati E, Ahmadi S. Component predicted by selfesteem and marital happiness of married women. Woman in Culture Arts. 2011;3(1):37-52.

23. Bramon CL. Marriage in Michigan, factors that affect satisfaction IPPSR; 2000.

24. Vaijayanthimala K, Kumari K, Panda P. Socio-economic heteronomy and marital satisfaction. Journal of Human Ecology. 2004;15(1):9-11.

25. Trudel G. Sexual and marital life: Results of a survey. Journal of Sex and Marital Therapy. 2002;28(3):229-249.

26. Bograd R, Spilka B. Self-disclosure and marital satisfaction in mid-life and late-life remarriages. Int J Aging Hum Dev. 1996;42(3):161-172.

27. KL Chou, I Chi. Determinants of life satisfaction in Hong Kong Chinese elderly: A longitudinal study. Aging and Mental Health. 1999;3(4):328335 .

28. White L, Edwards JH. Emptying the nest and parental well-being: An analysis of national panel data. American Sociological Review. 1990;55:235-242.

29. Alder Emily S. Age, Education Level, and Length of Courtship in Relation to Marital Satisfaction. Pacific University. India: Springer; 2010.

30. Telsiz M. Adolescents views on the parental roles: A Turkish study. International Journal of Sociology of family. 1998;28(4):69-77.

31. Addis IB, Van Den Eeden SK, Wassel Fyr CL, et al. Sexual activity and function in middle-aged and older women. Obstet Gynecol. 2006;107(4):755-764.

32. Homish GG, Leonard KE, Kozlowski LT, et al. The longitudinal association between multiple substance use discrepancies and marital satisfaction. Addiction. 2009;104(7):1201-1209.

33. Blumel JE, Castelo Branco C, Binfa L, et al. Quality of life after menopause; a population study. Maturitas. 2000;34:17-23.

34. Dennerstein L, Dudley E, Guthrie J, et al. Life satisfaction, Symptoms and the menopausal transition. Medscape Womens Health. 2000;5(4):E4.

35. Kalmijn M. Father Involvement in Childrearing and the Perceived Stability of Marriage. Journal of Marriage and the Family. 1999;61(2):409-421.

36. Oberzaucher E, Grammer K. Ageing, mate preferences and sexuality: A mini-review. Gerontology. 2009;55:371-378. 